\title{
Efeito do substrato e de diferentes tratamentos pré-germinativos na germinação de sementes de Tento - Ormosia paraensis Ducke (Fabaceae)
}

\author{
Cândida Lahís Mews ${ }^{1 *}$ \\ Divino Vicente Silvério ${ }^{2}$ \\ Henrique Augusto Mews $^{3}$ \\ Roberta Thays dos Santos Cury ${ }^{1}$ \\ ${ }^{1}$ Instituto de Pesquisa Ambiental da Amazônia-IPAM \\ Rua Horizontina, 104, CEP 78.640-000, Canarana-MT, Brasil \\ ${ }^{2}$ Universidade de Brasília-UnB, Programa de Pós-Graduação em Ecologia \\ CEP 70.910-900, Brasília-DF, Brasil \\ ${ }^{3}$ Universidade de Brasília-UnB, Programa de Pós-Graduação em Ciências Florestais \\ Caixa Postal 4357, CEP 70.919-970, Brasília-DF, Brasil \\ *Autor para correspondência \\ tabebuia.6@gmail.com
}

Submetido em 04/04/2011

Aceito para publicação em 01/10/2011

\section{Resumo}

Este estudo objetivou avaliar a eficácia de tratamentos pré-germinativos em diferentes substratos para superar a dormência de sementes de Ormosia paraensis Ducke. Foram avaliados quatro tratamentos prégerminativos: 1) escarificação mecânica, 2) escarificação mecânica e embebição em água, 3) choque térmico, e 4) controle. As sementes tratadas foram plantadas em diferentes substratos: areia, serragem e solo florestal. Em cada substrato foram utilizadas três réplicas de 50 sementes para cada tratamento pré-germinativo (total de 1.800 sementes). Para verificar possíveis diferenças e interação entre os tratamentos pré-germinativos e os substratos empregou-se uma ANOVA fatorial. Adicionalmente, aplicou-se o teste de Tukey $(p<0,05)$ para comparação de médias. A germinação das sementes não diferiu entre os diversos substratos testados $(p>0,05)$. Os tratamentos com maiores taxas de germinação foram escarificação mecânica $(28,4 \%)$ e escarificação mecânica com embebição em água (36,4\%), que não diferiram entre si, mas foram diferentes dos tratamentos choque térmico $(0,02 \%) \mathrm{e}$ controle $(2 \%)(p<0,05)$. Os tratamentos de escarificação aumentaram a germinação em 15 vezes e reduziram o tempo médio de germinação (MGT) em mais de 30 dias em comparação ao controle, indicando que a escarificação mecânica constitui um método viável para superação de dormência de sementes de O.paraensis.

Palavras-chave: Escarificação mecânica, Quebra de dormência, Reflorestamento, Viveiros florestais

\section{Abstract}

Substrate effect and different pre-germinative treatments on seed germination of Tento - Ormosia paraensis Ducke (Fabaceae). The aim of this study was to evaluate the efficacy of pre-germinative treatments in different substrates for dormancy-break of Ormosia paraensis Ducke seeds. Four pre-germinative treatments 
were evaluated: 1) mechanical scarification, 2) mechanical scarification and water soaking, 3) heat shock, and 4) control. The seeds treated were planted in different substrates: sand, sawdust, and forest soil. In each substrate, three replicas of 50 seeds for each pre-germinative treatment (total of 1,800 seeds) were used. To assess possible differences and interaction between the pre-germinative treatments and the substrates a factorial ANOVA was used. Furthermore, the Tukey test $(p<0.05)$ was applied to compare the mean values. The seeds germination did not differ between the diverse substrates tested $(p>0.05)$. The treatments with higher germination rates were mechanical scarification (28.4\%) and mechanical scarification with water soaking $(36.4 \%)$, which did not differ from each other, but they were different from the heat shock $(0.02 \%)$ and control $(2 \%)(p<0.05)$ treatments. The scarification treatments increased germination by 15 times and decreased the mean germination time (MGT) in more than 30 days when compared to control, indicating that mechanical scarification is a feasible method for dormancy-break of $O$. paraensis seeds.

Key words: Dormancy-break, Forest nurseries, Mechanical scarification, Reforestation

\section{Introdução}

A gama de espécies com potencial para recuperação de florestas e áreas degradadas é grandiosa e vem ganhando importância em programas de reposição florestal (VIEIRA et al., 2001), no entanto, muitas espécies nativas não são incluídas em plantios heterogêneos devido às dificuldades para a produção de mudas (GALVÃO; PORFÍRIO-DA-SILVA, 2005). Entre os principais fatores que dificultam a produção de mudas em viveiro e as iniciativas de recuperação de áreas degradadas, destacam-se a dormência física ou fisiológica de algumas sementes e a falta de informação sobre a germinação e substratos adequados ao estabelecimento das plântulas (CARDOSO, 2004).

Como consequência, frequentemente registrase limitada riqueza de espécies empregadas em estratégias de restauro florestal, ocasionando plantios bastante homogêneos que podem não favorecer espécies pertencentes a diferentes grupos ecológicos ou grupos funcionais, como recomendado por Hahn et al. (2006). Além disso, os referidos autores destacam que a dormência tegumentar associada à escassez de informações sobre a germinação de algumas sementes dificulta a determinação dos tratamentos prégerminativos e dos regimes de irrigação e adubação mais apropriados para garantir maior germinação das sementes e vitalidade das plântulas.

Apesar desses empecilhos, as iniciativas de produção de mudas nativas têm recebido destaque em ações de recuperação florestal em regiões que constantemente vem sofrendo perturbações ecológicas, como é o caso da região da bacia do Rio Xingu, que se encontra frequentemente sujeita a alterações antrópicas, relacionadas principalmente às intensas atividades agropecuárias e à exploração madeireira (NEPSTAD et al., 1999; SEPLAN/MT, 1999; KUNZ et al., 2008). Buscando reverter tal situação, diversos setores da sociedade do Xingu estão se mobilizando, no âmbito da Campanha Y Ikatu Xingu, para implantar iniciativas de preservação e recuperação de Áreas de Preservação Permanente e comunidades florestais (CAMPOS FILHO, 2009). Entretanto, a falta de conhecimento sobre as espécies nativas da região tem sido um desafio para a produção de mudas.

Dentre as espécies que apresentam potencial silvicultural encontra-se Ormosia paraensis Ducke, conhecida popularmente como tento ou olho-de-cabra. A referida espécie possui hábito arbóreo e ocorre em ampla distribuição nas florestas ombrófilas densas e capoeiras da Amazônia. Ormosia paraensis constitui uma espécie amplamente usada pela indústria madeireira, para a produção de artesanato, além de ser apontada como espécie de grande potencial para o emprego em iniciativas de recuperação de áreas degradadas na Amazônia, visto o seu potencial para fixação de nitrogênio (MOREIRA et al., 1992; PAULA; ALVES, 1997; CARNEIRO et al., 1998; RIBEIRO et al., 1999). Todavia, as informações básicas sobre a ecologia, biologia e fisiologia de $O$. paraensis ainda são incipientes. Buscando fornecer informações que contribuam para a produção de mudas de $O$. paraensis em viveiro, o objetivo do presente estudo foi avaliar a germinação de suas sementes submetidas a quatro tratamentos pré-germinativos em diferentes substratos. 


\section{Material e Métodos}

O presente estudo foi realizado no viveiro de mudas coberto com telas de poliolefinas de cor preta (sombrite), com nível de sombreamento de $70 \%$, no Instituto de Pesquisa Ambiental da Amazônia - IPAM (1304'35"S e $\left.52^{\circ} 23^{\prime} 08^{\prime \prime} \mathrm{W}\right)$. O viveiro foi instalado na Fazenda Tanguro, porção sudeste da Bacia Amazônica, área limítrofe entre os Biomas Cerrado e Floresta Amazônica, município de Querência - MT.

Foram utilizadas 1.800 sementes maduras, intactas e de aparência externa saudável de $O$. paraensis. O lote de sementes foi coletado manualmente, direto do solo, sob matrizes pré-selecionadas e distribuídas aleatoriamente em um trecho de floresta preservada. As sementes foram submetidas a quatro tratamentos para superação da dormência: 1) escarificação mecânica superficial na região oposta ao eixo embrionário, utilizando-se lixa número 120 (ES); 2) escarificação mecânica superficial na região oposta ao eixo embrionário, utilizando-se lixa número 120 e posterior pré-embebição em água em temperatura ambiente por $\left.24 \mathrm{~h}\left(\mathrm{ES} / \mathrm{H}_{2} \mathrm{O}\right) ; 3\right)$ choque térmico úmido, submetendo as sementes à água quente $\left(100^{\circ} \mathrm{C}\right)$ por $25 \mathrm{~min}$ e, posteriormente, à água gelada $\left(5^{\circ} \mathrm{C}\right)$ por $\left.25 \mathrm{~min}(\mathrm{CT}) ; 4\right)$ testemunhas sem tratamento (controle; ST). Posteriormente, foi feita a semeadura utilizando-se três substratos diferentes: areia, serragem (maravalha) e solo florestal. Os resultados analíticos da amostra do solo apontam concentrações de $\mathrm{P}=5,7 \mathrm{mg} /$ $\mathrm{dm}^{3}, \mathrm{~K}=21 \mathrm{mg} / \mathrm{dm}^{3}, \mathrm{Al}=1,1 \mathrm{cmol}_{\mathrm{c}} / \mathrm{dm}^{3}$ e Matéria orgânica $=42,2 \mathrm{~g} / \mathrm{dm}^{3}$. A areia e a serragem foram esterilizadas via calor com auxílio de um maçarico. Em cada substrato foram utilizadas três réplicas de 50 sementes para cada tratamento pré-germinativo. A areia e a serragem, utilizadas como substrato, foram acondicionadas em bandejas plásticas perfuradas no fundo e preenchidas com $5 \mathrm{~cm}$ de cada substrato. Para o solo florestal foram utilizados sacos plásticos próprios para produção de mudas $(15 \times 20 \mathrm{~cm})$. Após a semeadura, as sementes foram cobertas com uma fina camada de aproximadamente $2 \mathrm{~cm}$ de substrato.

O experimento foi irrigado duas vezes ao dia, no período da manhã e no fim da tarde. O número de sementes germinadas foi avaliado em intervalos de sete dias até o final do pico de germinação, sendo consideradas germinadas todas as sementes cujo caulículo emergiu na superfície do substrato. Após tal período, a coleta de dados foi efetuada quinzenalmente por período de até 129 dias.

A velocidade de germinação foi calculada a partir do tempo médio de germinação (MGT), empregandose a fórmula $\mathrm{MGT}=\sum\left(\mathrm{t}^{*} \mathrm{n}\right) / \sum \mathrm{n}$, onde $t$ é o tempo em dias, sendo zero o dia da semeadura, e $n$ o número de sementes germinadas no dia $t$ (BEWLEY; BLACK, 1994). Para verificar a existência de interação entre os tratamentos pré-germinativos e os substratos para a germinação das sementes e possíveis diferenças entre os mesmos foi realizada uma ANOVA fatorial (ZAR, 1999). Adicionalmente, utilizou-se uma ANOVA de um fator seguida de teste de Tukey $(p<0,05)$ para comparação de médias dentro dos tratamentos pré-germinativos e dos substratos (ZAR, 1999). A normalidade dos dados foi verificada pelo teste de Kolmogorov-Smirnov (KS) (SIEGEL; CASTELLAN-JÚNIOR, 1988) e a homogeneidade das variâncias foi verificada por meio do Teste de Levene (ZAR, 1999). Os cálculos foram realizados empregando-se programa BioEstat 5.0 (AYRES et al., 2007).

\section{Resultados}

Os resultados encontrados no presente estudo indicam que não houve interação significativa entre os tratamentos pré-germinativos e os três tipos de substrato $(\mathrm{F}=2,070 ; p=0,094)$. As médias do número de sementes de $O$. paraensis que germinaram para os substratos areia $(7,16 \pm 8,66)$, serragem $(10,58 \pm 11,64)$ e solo florestal $(7,50 \pm 8,54)$ não diferiram significativamente entre si $(\mathrm{F}=2,371 ; p=0,113)$. Entretanto, foram significativas as diferenças entre as médias do número de sementes que germinaram nos tratamentos com escarificação mecânica $(14,22 \pm 8,21)$, escarificação mecânica associada à pré-embebição em água $(18 \pm 6,87)$, choque térmico $(0,11 \pm 0,33)$ e controle $(1,11 \pm 1,45)(\mathrm{F}=99,495 ; p<0,001)$ (Figura 1).

As taxas de germinação total para o tratamento com escarificação mecânica associada à embebição em água $(36,4 \%)$ e do tratamento com escarificação mecânica 
$(28,4 \%)$ não diferiram entre si, porém apresentaram taxas de germinação significativamente maiores em relação aos tratamentos choque térmico e controle (Figura 1).

As primeiras sementes germinadas foram observadas 28 dias após a semeadura, sendo quatro sementes escarificadas mecanicamente e 28 escarificadas mecanicamente e pré-embebidas em água. No tratamento controle, as sementes começaram a germinar após 35 dias e no $56^{\circ}$ dia após a semeadura, $87,8 \%$ das sementes pré-embebidas em água já haviam emergido (Figura 1). O tempo médio de germinação (MGT) para os tratamentos $\mathrm{ES} / \mathrm{H}_{2} \mathrm{O}$ (42 dias) e $\mathrm{ES}$ (49 dias) foi 38 e 31 dias mais curto, respectivamente, em relação ao tempo médio de germinação do tratamento controle (80 dias).

FIGURA 1: Taxa de germinação de sementes de Ormosia paraensis submetidas a diferentes tratamentos prégerminativos em relação ao tempo de plantio. Linhas seguidas pela mesma letra não diferem entre si pelo teste de Tukey $(p<0,05)$.

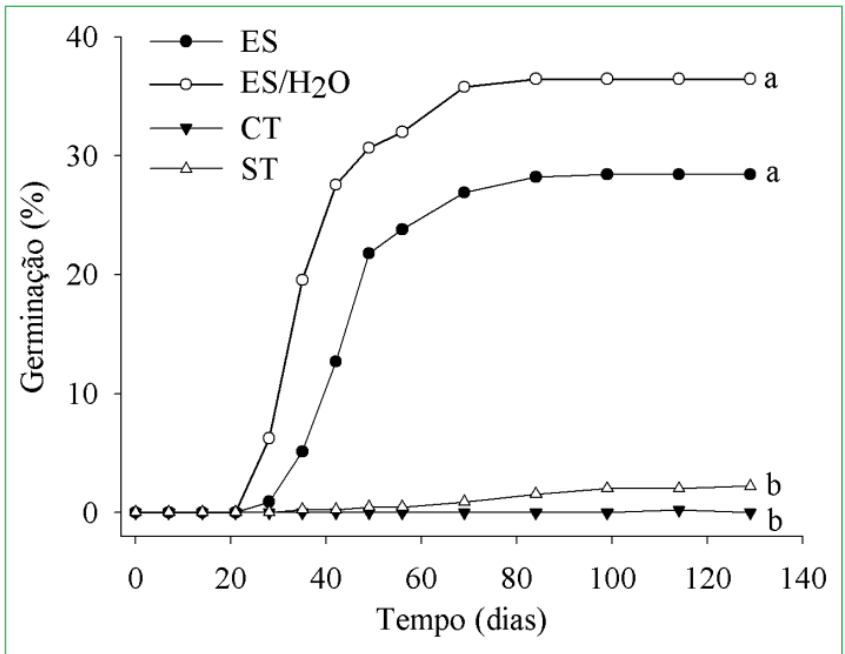

\section{Discussão}

Os tratamentos que empregaram técnicas de escarificação mecânica nas sementes de $O$. paraensis resultaram em aumento de 15 vezes na taxa de germinação em relação ao tratamento controle. Aumentos expressivos na germinação também foram constatados por Ribeiro et al. (2009), escarificando sementes de Adenanthera pavonina L. (aumento de 96\% na taxa de germinação), por Franco e Ferreira (2002), em sementes de Didymopanax morototoni (Aubl.) Decne. et Planch (aumento de 16\%) e por Marques et al. (2004), com sementes de Ormosia arborea (Vell.) Harms (aumento de $65 \%$ ) em relação aos seus respectivos tratamentos controle. Os resultados encontrados no presente estudo e nos trabalhos comparados sugerem que a escarificação mecânica constitui um eficiente tratamento para superar a dormência tegumentar das sementes em várias espécies, embora os resultados possam ser diferentes em função das peculiaridades de cada espécie e das diferenças nas metodologias empregadas.

A dormência nas sementes duras, como é o caso de $O$. paraensis, é atribuída à impermeabilidade do tegumento, sendo mais indicada, neste caso, a promoção de aberturas nas sementes que permitam a embebição, o que é feito frequentemente pelos processos de escarificação (FRANCO; FERREIRA, 2002). As sementes de tento que foram mecanicamente escarificadas aumentaram visivelmente de tamanho e adquiriram uma textura mais tenra após a embebição em água. A pressão criada com a absorção de água promoveu um aumento no volume das substâncias coloidais, resultando no rompimento dos tegumentos das sementes. O processo de embebição reativa o metabolismo e aumenta a atividade respiratória, resultando no desenvolvimento do embrião e germinação da semente (BEWLEY, 1997; FERREIRA; BORGHETTI, 2004). No entanto, a escarificação pode danificar as sementes pela fricção demasiada, de modo que deve ser efetuada com cuidado para evitar lesões no embrião e não comprometer a qualidade das sementes (MACDONALD; COPELAND, 1997; MEDEIROS FILHO et al., 2002).

Segundo Ferreira e Borghetti (2004), o método de choque térmico ajuda no processo de quebra de dormência, mas isso depende da espécie, pois em algumas sementes ocorre a morte do embrião quando elas são colocadas em água a $100^{\circ} \mathrm{C}$. Todavia, mudanças nas temperaturas e no tempo de exposição das sementes podem apresentar resultados diferenciados. Bell e Williams (1998) mencionam que as espécies respondem diferentemente à exposição ao calor e que não há relação comprovada entre a espessura das camadas que compõem o tegumento das sementes e a tolerância ao calor. Segundo Martins et al. (1992), a eficiência de tratamentos pré-germinativos, bem como sua duração, 
dependem do grau de dormência apresentado pelas sementes. Desta forma, a ausência de germinação no tratamento choque térmico precisa ser mais bem investigada, visto que a temperatura $\left(100^{\circ} \mathrm{C}\right)$ e o tempo de exposição utilizados $(25 \mathrm{~min})$ podem não ter sido suficientes para superar a dormência das sementes ou podem até ter ocasionado a morte do embrião.

A germinação das sementes no tratamento controle ocorreu ao longo do período de estudo, sem pico definido. Uma possível explicação seria o fato de que sementes expostas às condições ambientais por períodos prolongados teriam a dormência tegumentar parcialmente superada com o passar do tempo (BASKIN; BASKIN, 2000; CARDOSO, 2004). Segundo Teketay (1996) e Baskin e Baskin (2000), sementes com tegumento impermeável não apenas permanecem viáveis por um longo tempo, como também existe a possibilidade de, em condições naturais, diferentes porções da população de sementes tornarem-se permeáveis e germinarem. Regimes de temperaturas adequadas, teor de água na semente e ponto de maturidade fisiológica são fatores cruciais à superação da dormência de sementes duras no meio natural (CARDOSO, 2004).

Sob condições de viveiro, a quantidade de água e luz foi muito semelhante para os três tipos de substratos utilizados. As taxas de germinação das sementes nos substratos analisados não diferiram significativamente entre si. Resultados similares também foram observados em substratos papel e esfagno, com sementes escarificadas de Ormosia arborea (Vell.) Harms (MARQUES et al., 2004). Segundo Ferreira e Borghetti (2004), o fato de a taxa de germinação não diferir entre os diferentes substratos pode ser explicado pela independência parcial das plântulas, nos seus estádios iniciais de desenvolvimento, aos nutrientes do substrato, sendo abastecidas pelos carboidratos da semente até que ocorra a protrusão da raiz primária e a emergência das primeiras folhas.

O significado biológico e ecológico da impermeabilidade imposta pelo tegumento de algumas sementes tem sido bastante discutido (BEWLEY, 1997; BASKIN; BASKIN, 2000). Esta é uma característica valiosa para a sobrevivência das espécies sob condições adversas, uma vez que conseguem livrar as sementes de períodos inóspitos para sua germinação (BORGES et al., 1982; BASKIN; BASKIN, 2000).

Entre os diferentes tratamentos pré-germinativos testados sob condições de viveiro, a escarificação mecânica seguida ou não de pré-embebição em água constituiu o método mais eficiente para a superação da dormência tegumentar apresentada pelas sementes de O. paraensis. Com tal tratamento, é possível aumentar a capacidade e a velocidade da germinação, independentemente dos substratos utilizados. Os resultados apresentados neste estudo fornecerão subsídios para novas pesquisas sobre a quebra de dormência em sementes duras e informações úteis à produção de mudas em viveiro para o emprego em plantios e reflorestamentos.

\section{Agradecimentos}

Ao Instituto de Pesquisa Ambiental da Amazônia - IPAM por disponibilizar o campo experimental e pelo apoio logístico durante o estudo. Aos técnicos de campo do IPAM pelo auxílio na coleta das sementes.

\section{Referências}

AYRES, M.; AYRES JR. M.; AYRES, D. L.; SANTOS, A. A. S. BioEstat 5.0: Aplicações estatísticas na área das ciências biomédicas. Belém: Sociedade Civil de Mamirauá, 2007. 364 p.

BASKIN, J. M.; BASKIN, C. C. Evolutionary considerations of claims for physical dormancybreak by microbial action and abrasion by soil particles. Seed Science Research, Cambridge, v. 10, p. 409-413, 2000.

BELL, D. T.; WILLIAMS, D. S. Tolerance of thermal shock in seeds. Australian Journal of Botany, Collingwood, v. 46, n. 2, p. 221-233, 1998.

BEWLEY, J. D. Seed germination and dormancy. The Plant Cell, Waterbury, v. 9, n. 7, p. 1055-1066, 1997.

BEWLEY, J. D.; BLACK, M. Seeds: physiology of development and germination. New York: Plenum Press, 1994. 445 p.

BORGES, E. E. L.; BORGES, R. C. G.; CANDIDO, J. F.; GOMES, J. M. Comparação de métodos de quebra de dormência em sementes de copaíba. Revista Brasileira de Sementes, Londrina, v. 4, n. 1, p. 9-12, 1982.

CAMPOS FILHO, E. M. Coleção plante as árvores do Xingu e Araguaia: guia de identificação. São Paulo: Instituto Socioambiental, 2009. $295 \mathrm{p}$

CARDOSO, V. J. M. Domência: estabelecimento do processo. In: FERREIRA, A. G.; BORGHETTI, F. (Eds). Germinação: do básico ao aplicado. Porto Alegre: Artmed, 2004. p. 95-108. 
CARNEIRO, M. A. C.; SIQUEIRA, J. O.; MOREIRA, F. M. S.; CARVALHO, D.; BOTELHO, S. A. JUNIOR, O. J. S. Micorriza arbuscular em espécies arbóreas e arbustivas de ocorrência no Sudeste do Brasil. Nota Técnica Cerne, Lavras, v. 4, n. 1, p. 129$145,1998$.

FERREIRA, A. G.; BORGHETTI, F. Germinação: do básico ao aplicado. Porto Alegre: Artmed, 2004. 316 p.

FRANCO, E. T. H.; FERREIRA, A. G. Tratamentos prégerminativos em sementes de Didymopanax morototoni (Aubl.) Decne. et Planch. Ciência Florestal, Santa Maria, v. 12, n. 1, p. $1-10,2002$.

GALVÃO, A. P. M.; PORFÍRIO-DA-SILVA, V. Restauração florestal: fundamentos e estudos de caso. Colombo: EMBRAPA FLORESTAS, 2005. 139 p.

HAHN, C. M.; OLIVEIRA, C.; AMARAL, E. M.; RODRIGUES, M. S.; SOARES, P. V. Recuperação florestal: da semente à muda. São Paulo: SMA, 2006. 144 p.

KUNZ, S. H.; IVANAUSKAS, N. M.; MARTINS, S. V.; SILVA, E.; STEFANELLO, D. Aspectos florísticos e fitossociológicos de um trecho de Floresta Estacional Perenifólia na Fazenda Trairão, Bacia do rio das Pacas, Querência-MT. Acta Amazonica, Manaus, v. 38, n. 2, p. 245-254, 2008.

MACDONALD, M. B.; COPELAND, L. O. Seed production: principles and practices. New Jersey: Chapmam e Hall, 1997. 749 p.

MARQUES, M. A.; RODRIGUES, T. J. D.; DE PAULA, R. C. Germinação de sementes de Ormosia arborea (Vell.) Harms submetidas a diferentes tratamentos pré-germinativos. Científica, Jaboticabal, v. 32, n. 2, p. 141-146. 2004.

MARTINS, C. C.; CARVALHO, N. M.; OLIVEIRA, A. P. Quebra de dormência de sementes de sabia. (Mimosa caesalpiniaefolia Benth.). Revista Brasileira de Sementes, Londrina, v. 14, n. 1, p. 5-8, 1992.

MEDEIROS FILHO, S.; FRANÇA, E. A.; INNECCO, R. Germinação de sementes Operculina macrocarpa (L.) Farwel e Operculina alata (Ham.) Urban. Revista Brasileira de Sementes, Londrina, v. 24, n. 2, p. 102-107, 2002.
MOREIRA, F. M. S.; SILVA, M. F.; FARIA, S. M. Occurence of nodulation in legume species in the amazon region. New phytologist, Oak Ridge, v. 121, p. 563-570, 1992.

NEPSTAD, D. C.; VERISSIMO, A.; ALENCAR, A.; NOBRE, C.; LIMA, E.; LEFEBVRE, P.; SCHLESINGER, P.; POTTER, C.; MOUTINHO, P.; MENDOZA, E.; COCHRANE, M.; BROOKS, V. Large-escale impoverishment of Amazonian forests by logging and fire. Nature, London, v. 398, p. 505-508, 1999.

PAULA, J. E.; ALVES, J. L. H. Madeiras nativas: anatomia, dendrologia, dendrometria, produção e uso. Brasília: Fundação Mokiti Okada - MOA, 1997. 543 p.

RIBEIRO, J. E. L. S.; HOPKINS, M. J. G.; VICENTINE, A.; SOTHERS, C. A.; COSTA, M. A. S.; BRITO, J. M.; SOUZA, M. A. D.; MARTINS, L. H. P.; LOHMANN, L. G.; ASSUNÇÃO, P. A. C.; PEREIRA, E. C.; SILVA, C. F.; MESQUITA, M. R.; PROCOPIO, L. C. Flora da reserva Ducke: guia de identificação das plantas vasculares de uma floresta de terre-firme na Amazônia Central. Manaus: INPA, 1999. 816 p.

RIBEIRO, V. V.; BRAZ, M. S. S.; BRITO, N. M. Tratamentos para superar a dormência de sementes de Tento. Revista Biotemas, Florianópolis, v. 22, n. 4, p. 25-32, 2009.

SEPLAN/MT - SECRETARIA DE ESTADO DE PLANEJAMENTO E COORDENAÇÃO GERAL DE MATO GROSSO. Dados secundários do DSEE/MT: Zoneamento. 1999. Cuiabá: SEPLAN. Versão eletrônica.

SIEGEL, S.; CASTELLAN-JUNIOR, N. J. Nonparametric statistics for the behavioral sciences. New York: McGraw-Hill, $1988.399 \mathrm{p}$.

TEKETAY, D. The effect of different pre-sowing seed treatments, temperature and light on the germination of five Senna species from Ethiopia. New Forests, Sydney, v. 11, n. 2, p. 155-171, 1996.

VIEIRA, A. H.; MARTINS, E. P.; PEQUENO, P. L. L.; LOCATELli, M.; SOUZA, M. G. Técnicas de produção de sementes florestais. Porto Velho: EMBRAPA/CPAF, 2001. 4 p. (Circular Técnica, 205).

ZAR, J. H. Biostatistical analysis. New Jersey: Prentice Hall, 1999. $663 \mathrm{p}$. 